Pengembangan Rekayasa dan Teknologi, Vol 15, No. 2, December 2019, pp 96-106

p-ISSN: 1410-9840 \& e-ISSN: 2580-8850

http://journals.usm.ac.id/index.php/jprt/index

\title{
Studi Evaluasi Kebutuhan Pelayanan Pejalan Kaki Jalan Meruya Selatan, Kembangan, Jakarta Barat (Depan Univesitas Mercu Buana)
}

\author{
Nunung Widyaningsih. ${ }^{1}$, Sofyan Dimas Susena. ${ }^{2}$ \\ Jurusan Teknik Sipil Universitas Mercu Buana \\ ${ }^{1}$ nunung_widyaningsih@mercubuana.ac.id, ${ }^{2}$ sofyandimas36@gmail.com
}

\begin{abstract}
Pedestrians are a form of transportation that is not less numerous than other transportation, especially in the education area. It is necessary to re-evaluate existing pedestrian facilities because of changes in population in the region so pedestrian can feel comfortable and safe. And how LOS of the traffic flow there. In this analysis carried out on two rush hour days. In this study aims to evaluate the sidewalk in front of and across UMB, crossing facilities and traffic flow. The analysis related to the public works department directorate general of the clan of the directorate of engineering/No:011/T/Bt/1995 and Indonesian road capacity manual 1997. The result of the analysis show that LOS od sidewalk in front of and across UMB is B. The LOS of the traffic flow there is E. and evaluation of existing crossing facilities needs to be replaced with pelican crossing with a waiting stall.
\end{abstract}

Keyword : Level of performance services, pedestrians, traffic flows, sidewalks, crossing facilities

\begin{abstract}
Abstrak
Pejalan kaki adalah bentuk transportasi yang tidak kalah banyak dibandingkan transportasi lain terutama di kawasan pendidikan. Maka dari itu diperlukan evaluasi kembali terhadap fasilitas pejalan kaki yang ada karena perubahan populasi di kawasan tersebut agar pejalan kaki merasa nyaman ada aman. Dan bagaimana LOS arus lalu lintas pada daerah tersebut. Dalam analisa ini dilakukan pada dua hari pada jam sibuk. Pada penelitian ini bertujuan untuk mengevaluasi trotoar di depan dan di seberang UMB, fasilitas penyeberangan, dan arus lalu lintas. Analisa yang di gunakan berdasarkan Departemen Pekerjaan Umum Direktorat Jenderal Bina Marga Direktorat Bina Teknik /No:011/T/Bt/1995 dan MKJI 1997. Hasil analisa didapat bahwa LOS trotoar di depan dan seberang UMB adalah B. LOS arus lalu lintas di kawasan tersebut adalah E. Dan evaluasi fasilitas penyeberangan yang ada perlu diganti dengan pelican dengan lapak tunggu.
\end{abstract}

Kata Kunci : Tingkat pelayanan kinerja, pejalan kaki, arus lalu lintas, trotoar, fasilitas penyeberangan

\section{PENDAHULUAN}

\section{Latar Belakang}

Pejalan kaki merupakan bentuk transportasi yang tidak kalah banyak dibanding dengan transportasi kendaraan lain. Di sekitar kawasan pendidikan volume pejalan kaki cukup tinggi dibandingkan kawasan industri dan pemukiman. Oleh karena itu kebutuhan pejalan kaki adalah salah satu bagian yang penting dalam sistem transportasi jalan. Karakteristik pejalan kaki adalah salah satu faktor utama dalam perancangan, perencanaan maupun pengoperasian dari fasilitas - fasilitas transportasi yang ada. Disekitar Jalan Meruya Selatan, Kembangan, Jakarta Barat terdapat berbagai macam sarana pelayanan publik, ditunjang adanya kampus Universitas Mercu Buana, akibatnya kawasan tersebut menambah daya tarik sehingga muncul berbagai macam persoalan sosial yang terus tumbuh dan berkembang diseluruh sisi jalan serta kemacetan akibat jumlah pejalan kaki semakin meningkat. Oleh karena itu dibutuhkan evaluasi mengenai fungsi dari trotoar dan tempat penyebrangan. Bagaimana kebutuhan karakteristik, volume dan kepadatan pejalan kaki diharapkan dapat mengetahui tingkat pelayanan trotoar dan pendekatan yang bisa menyelesaikan persoalan antara pejalan kaki dan lalu lintas kendaraan. 
Pengembangan Rekayasa dan Teknologi, Vol 15, No. 2, December 2019, pp 96-106

p-ISSN: $1410-9840$ \& e-ISSN: 2580-8850

http://journals.usm.ac.id/index.php/jprt/index

\section{TINJAUAN PUSTAKA}

\section{PenentuanTrotoar}

Umumnya pada desain fasilitas untuk pejalan kaki, ruang adalah ukuran dasar dari keefektifannya. Kapasitas sama dengan 25 $\mathrm{ped} / \mathrm{menit} / \mathrm{ft}$. Pada tabel 1 menunjukkan kriteria untuk tingkat pelayanan pejalan kaki.

Fluktuasi jangka pendek terjadi terhadap sebagian besar aliran pejalan kaki karena pejalan kaki tiba dan berangkat secara acak, seperti yang terjadi pada trotoar. Apabila trotoar dan fasilitas faslitas lain menunjukkan efek pempletonan, disarankan bahwa lonjakan ini harus dibagi - bagi waktunya. Suatu perumusan yang menghubungkan laju aliran pleton maksimum dengan laju aliran rata - rata yaitu :

$$
\begin{aligned}
\frac{\text { Aliran pleton }}{\text { Arus Pleton }} & =\text { Aliran }(\text { Arus }) \text { rata }- \text { rata } \\
& +4
\end{aligned}
$$

Tabel 1 Kriteria LOS arus rata - rata untuk jalan orang dan trotoar

\begin{tabular}{cllcl}
\hline $\begin{array}{c}\text { Tingkat Pelayanan } \\
(\text { LOS })\end{array}$ & Ruang $\left(\mathbf{f t}^{2} / \mathbf{p e d}\right)$ & $\begin{array}{c}\text { Laju arus / aliran } \\
(\mathbf{p e d} / \mathbf{m e n i t} / \mathbf{f t})\end{array}$ & $\begin{array}{c}\text { Kecepatan } \\
(\mathbf{f t} / \mathbf{m e n i t})\end{array}$ & Rasio $(\mathrm{V} / \mathrm{S})$ \\
\hline $\mathrm{A}$ & $>60$ & $\leq 5$ & 270 & $\leq 0,21$ \\
$\mathrm{~B}$ & $>40-60$ & $>5$ & $250-255$ & $>0,21-0,31$ \\
$\mathrm{C}$ & $>24-40$ & $>7$ & $240-250$ & $>0,31-0,44$ \\
$\mathrm{D}$ & $>15-24$ & $>10-15$ & $225-240$ & $>0.44$ \\
$\mathrm{E}$ & $>8-15$ & $>15-23$ & $150-225$ & $>0.65$ \\
$\mathrm{~F}$ & $\leq 8$ & Beragam & 150 & Beragam
\end{tabular}

Sumber, TRB, 2000 ( Sumber : Skripsi Studi Kebutuhan Fasilitas Penyeberangan Di Kota Tangerang, Jakarta,2009 )

\section{Penentuan Fasilitas Penyeberangan}

Fasilitas pejalan kaki dan penyeberangan sebidang menurut Tata Cara Perencanaan Fasilitas Pejalan Kaki di Kawasan No : 011/T/Bt/1995 ada beberapa jenis penyeberangan sebidang yaitu zebra cross tanpa atau dengan pelindung dan pelikan tanpa atau dengan pelindung. Penyeberangan tanpa pelindung adalah penyeberangan yang tidak dilengkapi dengan pulau pelindung. Sedangkan penyeberangan dengan pelindung yaitu penyeberangan yang dilengkapi dengan pulau pelindung dan rambu peringatan awal bangunan pemisah untuk lalu lintas dua arah. Kriteria dalam memilih fasilitas penyeberangan sebidang didasarkan pada rumus:

$$
\mathbf{P V}^{2}
$$

Keterangan :

$\mathrm{P}=$ Arus Pejalan kaki yang meyeberang diruas jalan sepanjang $100 \mathrm{~m}$ tiap jamnya (orang/jam) $\mathrm{V}=$ Arus lalu lintas dalam dua arah tiap jamnya (Kendaraan/jam)

Nilai $\mathrm{P}$ dan $\mathrm{V}$ merupakan arus rata - rata pejalan kaki dan kendaraan dalam empat jam tersibuk. Secara keseluruhan penentuan fasilitas penyeberangan harus memenuhi pada Tabel 2

Tabel 2.3 Pemilihan fasilitas penyebrangan berdasarkan $\mathbf{P V}^{2}$

\begin{tabular}{llll}
\hline \multicolumn{1}{c}{$\mathbf{P V}^{2}$} & \multicolumn{1}{c}{$\mathbf{P}($ orang / jam) } & \multicolumn{1}{c}{ V(kendaraan / jam) } & \multicolumn{1}{c}{ Rekomendasi } \\
\hline$>10^{8}$ & $50-1100$ & $300-500$ & Zebra cross (Zc) \\
$>2 \times 10^{8}$ & $50-1100$ & $400-750$ & Zc dengan Lapak Tunggu \\
$>10^{8}$ & $50-1100$ & $>500$ & Pelican $(\mathrm{p})$ \\
$>10^{8}$ & $>1100$ & $>300$ & Pelican $(\mathrm{p})$ \\
$>2 \times 10^{8}$ & $50-1100$ & $>750$ & Pelican dengan Lapak Tunggu \\
$>2 \times 10^{8}$ & $>1100$ & $>400$ & Pelican dengan Lapak Tunggu \\
\hline
\end{tabular}

Sumber : Tata Cara Perencanaan Fasilitas Pejalan Kaki di Kawasan Perkotaan ( Departemen Pekerjaan Umum Direktorat Jenderal Bina Marga Direktorat Bina Teknik / No : 011/T/Bt/1995 ) 
Pengembangan Rekayasa dan Teknologi, Vol 15, No. 2, December 2019, pp 96-106

p-ISSN: 1410-9840 \& e-ISSN: 2580-8850

http://journals.usm.ac.id/index.php/jprt/index

\section{Penentuan LOS Arus Lalu Lintas}

MKJI (1997) mendefinisikan kapasitas sebagai arus maksimum yang melalui suatu titik di jalan yang dapat dipertahankan per satuan jam pada kondisi tertentu. Untuk jalan dua lajur dua arah, kapasitas ditentukan untuk arus dua arah ( kombinasi dua arah), tetapi untuk jalan dengan banyak lajur, arus dipisah per arah dan kapasitas ditentukan per lajur. Persamaan dasar untuk menghitung kapasitas ruas jalan dalam MKJI (1997) adalah sebagai berikut:

\section{C $=$ Co $\times$ FCw $\times$ FCSP $\times$ FCSF $\times$ FCCS}

Keterangan :

$\mathrm{C}=$ kapasitas $(\mathrm{smp} / \mathrm{jam})$

Co $=$ kapasitas dasar $(\mathrm{smp} / \mathrm{jam})$

$\mathrm{FCw}=$ faktor penyesuaian lebar jalan

FCSP = faktor penyesuaian pemisah arah

FCSF = faktor penyesuaian hambatan samping dan bahu jalan/kereb

FCCS = faktor penyesuaian ukuran kota
Derajat kejenuhan merupakan rasio volume terhadap kapasitas, sebagai faktor utama untuk menentukan tingkat kinerja simpang atau ruas jalan. Persamaan dasar derajat kejenuhan adalah

$$
D S=\frac{V}{C}
$$

Kriteria tingkat pelayanan pada ruas jalan ditetapkan berdasarkan nilai derajat kejenuhan ( DS ) yaitu sebagai rasio arus terhadap kapasitas, digunakan sebagai faktor utama untuk penentuan tingkat kinerja simpang dan segmen jalan. Jika volume meningkat kecepatan biasanya berkurang, kebebasan manuver juga berkurang disebabkan bertambah banyaknya jumlah kendaraan yang ada dan kenyamanan dalam mengemudi juga berkurang dikarenakan harus mengawasi gerakan kendaraan, karena banyak kendaraan di sekitarnya. Nilai derajat kejenuhan akan menunjukkan apakah segmen jalan tersebut memiliki masalah pada kapasitas atau tidak.

Tabel 3 Kriteria-kriteria tingkat pelayanan ruas jalan

\begin{tabular}{|c|c|c|}
\hline $\begin{array}{c}\text { Tingkat } \\
\text { Pelayanan } \\
\end{array}$ & Karakteristik - Karakteristik & Derajat Kejenuhan \\
\hline $\mathrm{A}$ & $\begin{array}{l}\text { Kondisi arus bebas dengan kecepatan tinggi, pengemudi dapat } \\
\text { memilih kecepatan yang diinginkan tanpa hambatan }\end{array}$ & $0-0,2$ \\
\hline B & $\begin{array}{l}\text { Arus stabil, tetapi kecepatan operasi mulai dibatasi oleh kondisi } \\
\text { lalu lintas. Pengemudi memiliki kebebasan yang cukup untuk } \\
\text { memilih kecepatan }\end{array}$ & $0,21-0,44$ \\
\hline $\mathrm{C}$ & $\begin{array}{l}\text { Arus stabil, tetapi kecepatan dan gerak kendaraan dikendalikan. } \\
\text { Pengemudi dibatasi dalam memilih memilih kecepatan }\end{array}$ & $0,45-0,74$ \\
\hline $\mathrm{D}$ & $\begin{array}{l}\text { Arus mendekati tidak stabil, kecepatan masih dikendalikan, masih } \\
\text { dapat ditolerir }\end{array}$ & $0,75-0,84$ \\
\hline $\mathrm{E}$ & $\begin{array}{c}\text { Volume lalu lintas mendekati atau berada pada kapasitas dan arus } \\
\text { yang tidak stabil, kecepatan kadang - kadang berhenti }\end{array}$ & $0,85-1,00$ \\
\hline $\mathrm{F}$ & $\begin{array}{l}\text { Arus yang terhambat, kecepatan rendah, volume dibawah } \\
\text { kapasitas, antrian panjang terjadi hambatan panjang }\end{array}$ & $>1,00$ \\
\hline
\end{tabular}

\section{Sumber : MKJI, 1997}

\section{METODE PENELITIAN}

\section{Jenis Penelitian}

Metode penelitian yang digunakan dalam survey ini adalah metode pengumpulan data dengan pengamatan secara langsung.

\section{Tempat dan Waktu Penelitian}

Lokasi penelitian akan di lakukan pada Jalan Meruya Selatan, Kembangan, Jakarta Barat di sepanjang jalur pejalan kaki pada trotoar di depan dan di seberang Universitas Mercu Buana.
Survey akan dilaksanakan selama dua hari pada hari Sabtu 2 Maret 2019 dan Senin.4 Maret 2019 pada jam sibuk yaitu pukul 06.00-08.00, pukul 12.00-14.00 dan pukul 16.00-18.00.

\section{Pengumpulan Data}

Pengumpulan data merupakan suatu cara untuk memperoleh keterangan - keterangan / data -data yang bersifat primer maupun sekunder yang akan dipakai untuk keperluan penelitian. Data-data tersebut adalah : 
Pengembangan Rekayasa dan Teknologi, Vol 15, No. 2, December 2019, pp 96-106

p-ISSN: $1410-9840$ \& e-ISSN: 2580-8850

http://journals.usm.ac.id/index.php/jprt/index

1. Data primer

Data primer merupakan data yang didapat dari hasil pengamatan di lapangan secara langsung yang terdiri dari :

a.Volume kendaraan

b.Volume pejalan kaki yang melintasi trotoar

c.Kecepatan pejlan kaki di trotoar

d.Kecepatan penyeberang jalann

e.Hambatan samping

f.Kecepatan kendaraan

g.Data geometrik jalan

h.Jumlah penyeberang jalan yang melewati ruas jalan

2. Data sekunder

Data sekunder merupakan data yang di dadapat dari instasi yang berwenang dengan penyediaan data yang berhubungan dengan masalah yang menjadi objek penelitian. Data sekunder meliputi peta lokasi dan dokumentasi.

\section{Teknik Pengumpulan Data}

Dalam pengambilan data diperlukan survey berikut :

\section{a. Pengukuran Geometrik Jalan}

Pengukuran geometrik jalan dilakukan pada pagi hari ( jam 06.00 ), karena pada pagi hari arus lalu lintas sepi dan tidak sepadat pada siang hari. Pengukuran ini meliputi lebar jalan dan, lebar trotoar.

\section{b. Survey Volume Kendaraan}

Survey Volume Kendaraan dapat dilaksanakan dengan melakukan pengamatan langsung dilapangan dengan cara menghitung jumlah kendaraan yang melintasi lokasi survey yang sudah ditentukan. Jumlah kendaraan dihitung pada dua arah arus kendaraan yang berbeda. Kendaraan yang diamati antara lain mobil sedan atau kijang, motor, bus dan truk. Seluruh kendaraan yang melintas akan dicatat kedalam survey.

\section{c. Survey Kecepatan}

Survey ini dilakukan untuk mendapatkan data kecepatan rata - rata kendaraan yang melewati jalan sepanjang $100 \mathrm{~m}$ dimana titik rencana berada di tengahnya. Kecepatan kendaraan ditentukan dengan menghitung jarak dibagi waktu yang ditempuh kendaraan untuk mencapai batas jarak yang telah ditentukkan.

Dalam survey ini diambil kecepatan rata - rata pada 3 kendaraan saja tiap interval 15 menit nya setiap 1 jam. Dengan begitu maka akan didapat data kecepatan kendaraan yang melewati titik penyeberangan.

Dari hasil survey ini akan mengasilkan data arus kendaraan ( V ) dalam satuan Kendaraan / Jam pada interval pada setiap empat jam aktif lalu lintas.

d. Survey Hambatan Samping

Survey hambatan samping dilakukan bersamaan dengan pencatatan volume kendaraan. Cara pengisian formulir penelitian yaitu dengan memasukkan hasil pengamatan mengenai frekuensi kejadian hambatan samping per jam per $100 \mathrm{~m}$ pada kedua sisi segmen yang akan diamati, seperti jumlah pejalan kaki berjalan atau menyeberang, jumlah kendaraan berhenti/parkir, jumlah kendaraan bermotor yang keluar/masuk dari lahan samping dan sisi jalan, dan arus kendaraan lambat. Selanjutnya frekuensi kejadian dikalikan dengan faktor berbobot kejadian per jam per $100 \mathrm{~m}$, kemudian kelas hambatan samping dapat ditentukan berdasarkan jumlah kejadian berbobot, termasuk semua tipe kejadian.

e. Survey Volume Pejalan Kaki Yang Menyusuri Trotoar

Survey ini dilakukan mengamati dengan menghitung jumlah pejalan kaki yang melintasi trotoar dimana menjadi titik lokasi survey.

f. Survey Volume Pejalan Kaki Yang Menyeberang Jalan

Dalam survey ini akan dilakukan pengamatan dengan menghitung jumlah pejalan kaki yang melewati zebra cross dan tidak melewati zebra cross pada titik lokasi survey. Data yang dapat diperoleh dari survey ini yaitu data Pejalan Kaki ( P) dalam jam sibuk.

\section{ANALISIS DATA}

Rekapitulasi hasil survey dan analisa pada hari Sabtu 2 Maret 2019 dan Senin 4 Maret 2019 dalam jam sibuk ditampilkan pada tabel berikut. 
Pengembangan Rekayasa dan Teknologi, Vol 15, No. 2, December 2019, pp 96-106

p-ISSN: $1410-9840$ \& e-ISSN: 2580-8850

http://journals.usm.ac.id/index.php/jprt/index

Analisa LOS Berdasarkan Arus Pleton

Tabel 4 Rekapitulasi Tingkat Pelayanan Pejalan Kaki Berdasarkan Arus Pletoon Trotoar Di Depan

Universitas Mercu Buana

\begin{tabular}{ccccccccc}
\hline \multirow{2}{*}{ WAKTU } & \multicolumn{3}{c}{ Arus Pletoon (ped/min/ft) } & \multicolumn{3}{c}{ Tingkat Pelayanan } \\
\cline { 2 - 9 } & \multicolumn{2}{c}{ Depan UMB } & \multicolumn{2}{c}{ Seberang UMB } & \multicolumn{2}{c}{ Depan UMB } & \multicolumn{2}{c}{ Seberang UMB } \\
& Senin & Sabtu & Senin & Sabtu & Senin & Sabtu & Senin & Sabtu \\
\hline $06.00-07.00$ & 4.52 & 4.53 & 4.95 & 4.90 & A & A & A & A \\
$07.00-08.00$ & 5.26 & 5.02 & 5.35 & 5.74 & B & B & B & B \\
$12.00-13.00$ & 5.30 & 5.34 & 5.07 & 6.00 & B & B & B & B \\
$13.00-14.00$ & 5.49 & 6.45 & 5.20 & 5.88 & B & B & B & B \\
$16.00-17.00$ & 6.08 & 6.07 & 5.64 & 6.14 & B & B & B & B \\
$17.00-18.00$ & 4.46 & 4.54 & 4.74 & 5.09 & A & A & A & B \\
\hline
\end{tabular}

Sumber : Hasil Perhitungan

Dari tabel 4 bahwa rata-rata tingkat pelayanan atau LOS pada trotoar di depan UMB adalah B dan arus pletoon terbesar terajdi pada pukul 13.00-14.00 pada hari Sabtu yaitu sebesar 6,45 . Sehingga terdapat ruang yang cukup untuk pejalan kaki mengatur kecepatannya secara bebas untuk mendahului dan menghindari konflik dari pejalan kaki lain. Pada tingkat ini pejalan kaki menyadari adanya pejalan kaki lain dan menanggapi kehadiran mereka dengan memilih lintasan berjalannya.

Sedangkan untuk trotoar di seberang UMB tingkat pelayanannya adalah B dengan arus pletoon terbesar terjadi pada pukul 16.00-17.00 pada hari Sabtu yaitu sebesar 6,14. Dimana pejalan kaki bebas bergerak dalam lintasan berjalannya. Dan kecepatan berjalannya pun bebas dan kemungkinan terjadi konflik antara pejalan kaki lain sangat kecil.

\section{Analisa LOS Berdasarkan Kepadatan Pejalan Kaki}

Tabel 5 Rekapitulasi Tingkat Pelayanan Pejalan Kaki Berdasarkan Kepadatan Senin 4 Maret 2019

\begin{tabular}{ccccc}
\hline \multirow{2}{*}{ Waktu } & \multicolumn{2}{c}{ Kepadatan $\left(\mathbf{p e d} / \mathbf{f t}^{2}\right)$} & \multicolumn{2}{c}{ Tingkat Pelayanan } \\
\cline { 2 - 5 } & Depan UMB & Seberang UMB & Depan UMB & Seberang UMB \\
\hline $06.00-07.00$ & 0.0275 & 0.0299 & $\mathrm{~A}$ & $\mathrm{~A}$ \\
$07.00-08.00$ & 0.0311 & 0.0336 & $\mathrm{~A}$ & $\mathrm{~A}$ \\
$12.00-13.00$ & 0.0410 & 0.0380 & $\mathrm{~A}$ & $\mathrm{~A}$ \\
$13.00-14.00$ & 0.0307 & 0.0287 & $\mathrm{~A}$ & $\mathrm{~A}$ \\
$16.00-17.00$ & 0.0333 & 0.0313 & $\mathrm{~A}$ & $\mathrm{~A}$ \\
$17.00-18.00$ & 0.0259 & 0.0266 & $\mathrm{~A}$ & $\mathrm{~A}$ \\
\hline
\end{tabular}

Sumber : Hasil Perhitungan

Tabel 6 Rekapitulasi Tingkat Pelayanan Pejalan Kaki Berdasarkan Kepadatan Sabtu 2 Maret 2019

\begin{tabular}{ccccc}
\hline \multirow{2}{*}{ Waktu } & \multicolumn{2}{c}{ Kepadatan $\left(\mathbf{p e d} / \mathbf{f t}^{\mathbf{2}}\right)$} & \multicolumn{2}{c}{ Tingkat Pelayanan } \\
\cline { 2 - 5 } & Depan UMB & Seberang UMB & Depan UMB & Seberang UMB \\
\hline $06.00-07.00$ & 0.0185 & 0.0204 & $\mathrm{~A}$ & $\mathrm{~A}$ \\
$07.00-08.00$ & 0.0223 & 0.0245 & $\mathrm{~A}$ & $\mathrm{~A}$ \\
$12.00-13.00$ & 0.0365 & 0.0408 & $\mathrm{~A}$ & $\mathrm{~A}$ \\
$13.00-14.00$ & 0.0364 & 0.0294 & $\mathrm{~A}$ & $\mathrm{~A}$ \\
$16.00-17.00$ & 0.0288 & 0.0309 & $\mathrm{~A}$ & $\mathrm{~A}$ \\
$17.00-18.00$ & 0.0248 & 0.0285 & $\mathrm{~A}$ & $\mathrm{~A}$ \\
\hline
\end{tabular}

Sumber : Hasil Perhitungan 
Pengembangan Rekayasa dan Teknologi, Vol 15, No. 2, December 2019, pp 96-106

p-ISSN: $1410-9840$ \& e-ISSN: 2580-8850

http://journals.usm.ac.id/index.php/jprt/index

Dari tabel 5 dan 6 bahwa kepadatan trotoar di depan UMB adalah A dimana dengan persyaratan bahwa LOS A adalah kepadatan $\leq$ 0,21 . Dengan kepadatan terbesar di depan UMB terjadi pada hari Senin 4 Maret 2019 pukul 12.00-
13.00 yaitu sebesar 0,0410 dan pada trotoar di seberang UMB tingkat pelayanannya adalah A dengan kepadatan terbesar pada hari Sabtu 2 Maret 2019 pukul 12.00-13.00 yaitu sebesar 0,0408 .

\section{Analisa LOS Berdasarkan Ruang Pejalan Kaki}

Tabel 7 Rekapitulasi Tingkat Pelayanan Pejalan Kaki Berdasarkan Ruang Pejalan Kaki Senin 4 Maret 2019

\begin{tabular}{|c|c|c|c|c|}
\hline \multirow{2}{*}{ Waktu } & \multicolumn{2}{|c|}{ Ruang $\left(\mathrm{ft}^{2} /\right.$ ped $)$} & \multicolumn{2}{c|}{ Tingkat Pelayanan } \\
\cline { 2 - 5 } & Depan UMB & Seberang UMB & Depan UMB & Seberang UMB \\
\hline $06.00-07.00$ & 37.81 & 35.44 & $\mathrm{~B}$ & $\mathrm{~B}$ \\
\hline $07.00-08.00$ & 32.18 & 30.10 & $\mathrm{~B}$ & $\mathrm{~B}$ \\
\hline $12.00-13.00$ & 24.72 & 26.84 & $\mathrm{~B}$ & $\mathrm{~B}$ \\
\hline $13.00-14.00$ & 33.59 & 35.85 & $\mathrm{~B}$ & $\mathrm{~B}$ \\
\hline $16.00-17.00$ & 30.15 & 32.50 & $\mathrm{~B}$ & $\mathrm{~B}$ \\
\hline $17.00-18.00$ & 39.37 & 38.28 & $\mathrm{~B}$ & $\mathrm{~B}$ \\
\hline
\end{tabular}

Sumber : Hasil Perhitungan

Tabel 8 Rekapitulasi Tingkat Pelayanan Pejalan Kaki Berdasarkan Ruang Pejalan Kaki Sabtu 2 Maret 2019

\begin{tabular}{|c|c|c|c|c|}
\hline \multirow{2}{*}{ Waktu } & \multicolumn{2}{|c|}{ Ruang $\left(\mathrm{ft}^{2} /\right.$ ped $)$} & \multicolumn{2}{c|}{ Tingkat Pelayanan } \\
\cline { 2 - 5 } & Depan UMB & Seberang UMB & Depan UMB & Seberang UMB \\
\hline $06.00-07.00$ & 54.82 & 49.81 & $\mathrm{~B}$ & $\mathrm{~B}$ \\
\hline $07.00-08.00$ & 45.13 & 41.06 & $\mathrm{~B}$ & $\mathrm{~B}$ \\
\hline $12.00-13.00$ & 28.09 & 25.87 & $\mathrm{~B}$ & $\mathrm{~B}$ \\
\hline $13.00-14.00$ & 30.17 & 35.65 & $\mathrm{~B}$ & $\mathrm{~B}$ \\
\hline $16.00-17.00$ & 35.09 & 33.82 & $\mathrm{~B}$ & $\mathrm{~B}$ \\
\hline $17.00-18.00$ & 40.41 & 35.32 & $\mathrm{~B}$ & $\mathrm{~B}$ \\
\hline
\end{tabular}

Sumber : Hasil Perhitungan

Dapat diketahui dari tabel 7 dan 8 bahwa tingkat pelayanan rata-rata ruang pejalan kaki pada trotoar di depan UMB dan di seberang UMB adalah B dengan persyaratan berdasarkan TRB, 2000 adalah ruang $>60$. Dengan ruang terbesar terjadi pada hari Sabtu 2 Maret 2019 pukul 06.00-
07.00 yaitu sebesar $54,82 \mathrm{ft}^{2} /$ ped di depan UMB dan pada hari Senin 4 Maret 2019 pukul 06.0007.00 sebesar $49,81 \mathrm{ft}^{2} /$ ped di seberang UMB. Dimana pejalan kaki bebas untuk mengatur lintasan berjalnnya dan bebas mengatur kecepatan berjalannya.

\section{Evaluasi Fasilitas Penyeberangan Dengan Analisa $\mathbf{P V}^{2}$}

Tabel 9 Rekapitulasi Penentuan Fasilitas Penyeberangan Senin 4 Maret 2019

\begin{tabular}{|c|c|c|c|c|c|c|}
\hline \multirow[t]{2}{*}{ Waktu (jam) } & \multirow{2}{*}{$\begin{array}{c}\mathbf{P} \\
\text { (orang/j } \\
\text { am) }\end{array}$} & \multirow{2}{*}{$\begin{array}{c}\mathrm{V} \\
(\mathbf{k e n d} / \mathbf{j a m})\end{array}$} & \multirow[t]{2}{*}{$\mathbf{P V}^{2}$} & \multirow{2}{*}{$\begin{array}{c}\begin{array}{c}\text { Syarat Pelican } \\
\text { Dengan Lapak } \\
\text { Tunggu }\end{array} \\
\mathrm{PV}^{2}\end{array}$} & \multicolumn{2}{|c|}{ Fasilitas Penyeberangan } \\
\hline & & & & & Yang telah ada & rekomendasi \\
\hline $06.00-07.00$ & 94 & 2023 & $3,8 \times 10^{8}$ & $>2 \times 10^{8}$ & Zebra Cross & $\begin{array}{l}\text { Pelican dengan } \\
\text { Lapak Tunggu }\end{array}$ \\
\hline 07.00-08.00 & 367 & 2560 & $2,4 \times 10^{9}$ & $>2 \times 10^{8}$ & Zebra Cross & $\begin{array}{l}\text { Pelican dengan } \\
\text { Lapak Tunggu }\end{array}$ \\
\hline $12.00-13.00$ & 284 & 2592 & $1,9 \times 10^{9}$ & $>2 \times 10^{8}$ & Zebra Cross & $\begin{array}{l}\text { Pelican dengan } \\
\text { Lapak Tunggu }\end{array}$ \\
\hline $13.00-14.00$ & 196 & 2620 & $1,3 \times 10^{9}$ & $>2 \times 10^{8}$ & Zebra Cross & Pelican dengan \\
\hline
\end{tabular}


Pengembangan Rekayasa dan Teknologi, Vol 15, No. 2, December 2019, pp 96-106 p-ISSN: $1410-9840$ \& e-ISSN: 2580-8850

http://journals.usm.ac.id/index.php/jprt/index

\begin{tabular}{ccccccc}
\hline Waktu (jam) & $\begin{array}{c}\mathbf{P} \\
\text { (orang/j } \\
\mathbf{a m})\end{array}$ & $\begin{array}{c}\mathbf{V} \\
\text { (kend/jam) }\end{array}$ & $\mathbf{P V}^{2}$ & $\begin{array}{c}\text { Syarat Pelican } \\
\text { Dengan Lapak } \\
\text { Tunggu }\end{array}$ & Fasilitas Penyeberangan \\
\cline { 4 - 6 } & & & $\mathrm{PV}^{2}$ & Yang telah ada & rekomendasi \\
\hline $16.00-17.00$ & 270 & 3451 & $3,2 \times 10^{9}$ & $>2 \times 10^{8}$ & Zebra Cross & $\begin{array}{c}\text { Lapak Tunggu } \\
\text { Pelican dengan } \\
\text { Lapak Tunggu }\end{array}$ \\
$17.00-18.00$ & 141 & 3899 & $2,1 \times 10^{9}$ & $>2 \times 10^{8}$ & Zebra Cross & $\begin{array}{c}\text { Pelican dengan } \\
\text { Papak Tunggu }\end{array}$ \\
Rata-Rata & 225.3 & 2857.5 & $1,8 \times 10^{9}$ & $>2 \times 10^{8}$ & Zebra Cross & $\begin{array}{c}\text { Pelican dengan } \\
\text { Lapak Tunggu }\end{array}$ \\
\hline
\end{tabular}

Sumber : Hasil Perhitungan

Tabel 10 Rekapitulasi Penentuan Fasilitas Penyeberangan Sabtu 2 Maret 2019

\begin{tabular}{|c|c|c|c|c|c|c|}
\hline \multirow[t]{2}{*}{ Waktu (jam) } & \multirow{2}{*}{$\begin{array}{c}\mathbf{P} \\
\text { (orang/j } \\
\text { am) }\end{array}$} & \multirow[t]{2}{*}{ V (kend/jam) } & \multirow[t]{2}{*}{$\mathbf{P V}^{2}$} & \multirow{2}{*}{$\begin{array}{c}\text { Syarat Pelican } \\
\text { Dengan Lapak } \\
\text { Tunggu }\end{array}$} & \multicolumn{2}{|c|}{ Fasilitas Penyeberangan } \\
\hline & & & & & Yang telah ada & Rekomendasi \\
\hline $06.00-07.00$ & 111 & 2062 & $4,7 \times 10^{8}$ & $>2 \times 10^{8}$ & Zebra Cross & $\begin{array}{l}\text { Pelican dengan } \\
\text { Lapak Tunggu }\end{array}$ \\
\hline $07.00-08.00$ & 205 & 2823 & $1,6 \times 10^{9}$ & $>2 \times 10^{8}$ & Zebra Cross & $\begin{array}{l}\text { Pelican dengan } \\
\text { Lapak Tunggu }\end{array}$ \\
\hline $12.00-13.00$ & 316 & 3235 & $3,3 \times 10^{9}$ & $>2 \times 10^{8}$ & Zebra Cross & $\begin{array}{l}\text { Pelican dengan } \\
\text { Lapak Tunggu }\end{array}$ \\
\hline $13.00-14.00$ & 359 & 2575 & $2,3 \times 10^{9}$ & $>2 \times 10^{8}$ & Zebra Cross & $\begin{array}{l}\text { Pelican dengan } \\
\text { Lapak Tunggu }\end{array}$ \\
\hline $16.00-17.00$ & 316 & 3344 & $3,5 \times 10^{9}$ & $>2 \times 10^{8}$ & Zebra Cross & $\begin{array}{l}\text { Pelican dengan } \\
\text { Lapak Tunggu }\end{array}$ \\
\hline $17.00-18.00$ & 129 & 3970 & $2,03 \times 10^{9}$ & $>2 \times 10^{8}$ & Zebra Cross & $\begin{array}{l}\text { Pelican dengan } \\
\text { Lapak Tunggu }\end{array}$ \\
\hline Rata-Rata & 239.3 & 3001.5 & $2,1 \times 10^{9}$ & $>2 \times 10^{8}$ & Zebra Cross & $\begin{array}{l}\text { Pelican dengan } \\
\text { Lapak Tunggu }\end{array}$ \\
\hline
\end{tabular}

Sumber : Hasil Perhitungan

Berikut grafik perbandingan dari penentuan fasilitas penyeberangan jalan pada hari Sabtu 2 Maret 2019 dan Senin 4 Maret 2019.

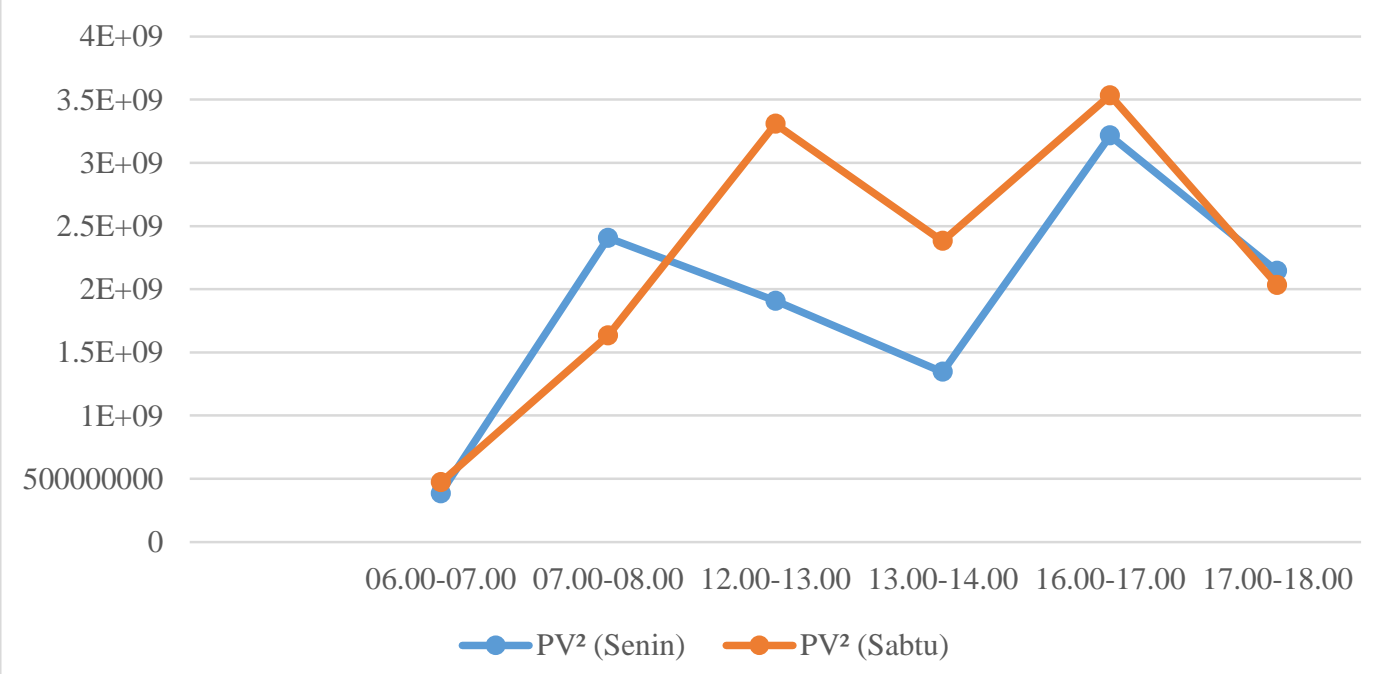

Gambar 1 Grafik perbandingan perhitungan $\mathrm{PV}^{2}$ dalam pengamatan dan perhitungan yang telah dilakukan

Berdasarkan evaluasi dari pangamatan dan perhitungan yang telah dilakukan dapat menjelaskan : a. Berdasarkan Tata Cara Perencanaan Fasilitas Pejalan Kaki di Kawasan Perkotaan ( Departemen Pekerjaan Umum Direktorat 
Pengembangan Rekayasa dan Teknologi, Vol 15, No. 2, December 2019, pp 96-106

p-ISSN: $1410-9840$ \& e-ISSN: 2580-8850

http://journals.usm.ac.id/index.php/jprt/index

Jenderal Bina Marga Direktorat Bina Teknik / No : 011/T/Bt/1995 ) bahwa rekomendasi fasilitas penyeberangan pada lokasi penelitian seharusnya menggunakan Pelican dengan pelapak tunggu. Karena fasilitas yang telah ada masih sangat beresiko yang mengancam keamanan bagi pejalan kaki yang menyeberang.

b. Dari lokasi pengamatan bahwa pada hari Senin 4 Maret 2019 dan Sabtu 2 Maret 2019 pukul 6 pagi sampai pukul 8 pagi, pukul 12 siang sampai pukul 2 siang, dan pukul 4 sore sampai pukul 6 sore merupakan jam tersibuk dari lalu lintas tersebut. Karena pada pagi hari merupakan jam berangkat sekolah, kerja, dan masuk kuliah sehingga kepadatan meningkat. Sedangkan pada siang hari merupakan waktu isoma, masuk kuliah, dan pulang kuliah sehingga menjadi jam sibuk. Lalu pada sore hari merupakan jam pulang bagi mahasiswa, staff maupun pekerja kantoran yang membuat jam tersebut menjadi jam sibuk.

\begin{abstract}
Analisa Ruas Jalan
Dalam analisa kecepatan kendaraan pada ruas Jalan Meruya Selatan di Depan Universitas Mercu Buana dilakukan pada pukul 16.00-18.00 karena pada jam tersebut arus lalu lintas kendaraan sangat padat. Perhitungan kecepatan kendaraan menggunakan rumus kecepatan ratarata ruang dengan jarak analisa $180 \mathrm{~m}$. Dan hasil analisa yang diuji kecepatannya adalah kendaraan pribadi dengan emp $=1$. Berikut akan ditampilkan kecepatan arus kendaraan pada tabel dibawah :
\end{abstract}

Tabel 11 Kecepatan Rata-Rata Ruang

\begin{tabular}{|c|c|c|c|c|}
\hline Waktu & $\begin{array}{c}\text { No } \\
\text { kendaraan }\end{array}$ & $\begin{array}{c}\text { Waktu tempuh LV } \\
\text { (detik) }\end{array}$ & 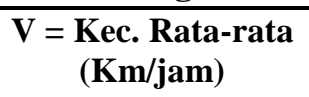 & $\begin{array}{l}\text { V = Kec. Rata- } \\
\text { rata (smp/jam) }\end{array}$ \\
\hline \multirow[t]{3}{*}{$16.00-16.15$} & 1 & 58.1 & 13.14 & 13.14 \\
\hline & 2 & 45.2 & & \\
\hline & 3 & 44.8 & & \\
\hline \multirow[t]{3}{*}{$16.15-16.30$} & 1 & 93.46 & 7.56 & 7.56 \\
\hline & 2 & 63.74 & & \\
\hline & 3 & 99.69 & & \\
\hline \multirow[t]{3}{*}{$16.30-16.45$} & 1 & 100.6 & 8.06 & 8.06 \\
\hline & 2 & 79.62 & & \\
\hline & 3 & 61.23 & & \\
\hline \multirow[t]{3}{*}{$16.45-17.00$} & 1 & 84.44 & 8.35 & 8.35 \\
\hline & 2 & 72.03 & & \\
\hline & 3 & 76.39 & & \\
\hline \multirow[t]{3}{*}{$17.00-17.15$} & 1 & 48.59 & 10.84 & 10.84 \\
\hline & 2 & 53.02 & & \\
\hline & 3 & 77.56 & & \\
\hline \multirow[t]{3}{*}{$17.15-17.30$} & 1 & 48.02 & 8.75 & 8.75 \\
\hline & 2 & 83.9 & & \\
\hline & 3 & 90.22 & & \\
\hline \multirow[t]{3}{*}{$17.30-.17 .45$} & 1 & 99.43 & 6.80 & 6.80 \\
\hline & 2 & 80.6 & & \\
\hline & 3 & 105.33 & & \\
\hline \multirow[t]{4}{*}{$17.45-18.00$} & 1 & 118.35 & 5.00 & 5.00 \\
\hline & 2 & 150.12 & & \\
\hline & 3 & 119.45 & & \\
\hline & Rata-Rata & & 8.56 & 8.56 \\
\hline
\end{tabular}

Sumber : Hasil Perhitungan 
Pengembangan Rekayasa dan Teknologi, Vol 15, No. 2, December 2019, pp 96-106

p-ISSN: $1410-9840$ \& e-ISSN: 2580-8850

http://journals.usm.ac.id/index.php/jprt/index

Perhitungan kapasitas jalan pada ruas jalan Meruya Selatan di depan Universitas Mercu Buana adalah sebagai berikut :

a. Kapasitas Dasar (Co)

Kapasitas jalan berdasarkan jenis jalan. Jalan yang di analisa adalah dua lajur dua arah tak terbagi $(2 / 2$ UD), maka didapat kapasitas dasar $=2900$ smp/jam (tabel 2.7)

b. Faktor penyesuaian lebar jalur lalu lintas $(\mathrm{FCw})$

Tipe jalan dua lajur dua arah tak terbagi (2/2 UD), Lebar jalur lalu lintas efektif (Wc) adalah $7 \mathrm{~m}$. Maka faktor penyesuaiannya adalah $1 \mathrm{Km} / \mathrm{jam}$ (tabel 2.8)

c. Faktor penyesuaian kapasitas untuk pemisahan arah (FCsp)

Berdasarkan tipe jalan 2/2 UD dan pemisahan arah maka faktor penyesuaian kapasitas untuk pemisahan arah adalah 1

d. Faktor penyesuaian kapasitas untuk hambatan samping (FCsf)

Ditentukan berdasarkan tipe jalan yaitu 2/2 UD, kelas hambatan samping yaitu $\mathrm{VH}$, dan jarak kerb-penghalang $\geq 2$. Maka dari tabel 2.10 didapat $=0,82$.

e. Faktor penyesuaian kapasitas untuk ukuran kota (FCcs)

Ditentukan berdasarkan jumlah penduduk di Jakarta Barat yaitu 2.529.126 juta penduduk maka faktor penyesuaiannya adalah 1 .

Perhitungan kapasitas

$\mathrm{C}=\mathrm{Co} \times \mathrm{FCw} \times \mathrm{FCsp} \times \mathrm{FCsf} \times \mathrm{FCcs}$

$\mathrm{C}=2900 \times 1 \times 1 \times 0,82 \times 1$

$\mathrm{C}=2378 \mathrm{smp} / \mathrm{jam}$

Berikut rekapitulasi derajat kejenuhan pada lokasi tersebut :

Tabel 12 Rekapitulasi Kapasitas Jalan

\begin{tabular}{ccc}
\hline Waktu & \multicolumn{2}{c}{ Kapasitas (C) (smp/jam) } \\
\cline { 2 - 3 } & Senin & Sabtu \\
\hline $06.00-08.00$ & 2378 & 2378 \\
$12.00-14.00$ & 2378 & 2378 \\
$16.00-18.00$ & 2378 & 2378 \\
\hline
\end{tabular}

Sumber : Hasil Perhitungan

Dari tabel diatas menyatakan bahwa kapasitas jalan di depan Universitas Mercu Buana adalah $2378 \mathrm{smp} / \mathrm{jam}$, hal itu menunjukan bahwa kapasitas jalan tersebut sangat tinggi terutama pada jam sibuk sehingga sering terjadi kemacetan.

Dalam perhitungan derajat kejenuhan digunakan rumus

$\mathrm{DS}=\mathrm{V} / \mathrm{C}$

Dimana :

$\mathrm{V}=$ Volume kendaraan yang melintasi jalan tersebut

$\mathrm{C}=$ Kapasitas jalan

Dari hasil analisa didapat pada pukul 16.00-18.00 Senin 4 Maret 2019 merupakan volume maksimum yaitu sebesar 1,41, sedangkan di hari Sabtu 2 Maret pukul 16.00-18.00 merupakan volume maksimum yaitu sebesar 0,92.

Berikut rekapitulasi dari hasil analisa dan perhitungan dilampirkan pada tabel 13 dan gambar perbandingan per hari dari derajat kejenuhan dibawah ini.

Tabel 13 Rekapitulasi Kapasitas Jalan

\begin{tabular}{ccc}
\hline Waktu & \multicolumn{2}{c}{ Total Derajat Kejenuhan } \\
\cline { 2 - 3 } & Senin & Sabtu \\
\hline $\mathbf{0 6 . 0 0 - 0 8 . 0 0}$ & 0.93 & 0.60 \\
$\mathbf{1 2 . 0 0 - 1 4 . 0 0}$ & 1.07 & 0.71 \\
$\mathbf{1 6 . 0 0 - 1 8 . 0 0}$ & 1.41 & 0.92 \\
\hline
\end{tabular}

Sumber : Hasil Perhitungan 
Pengembangan Rekayasa dan Teknologi, Vol 15, No. 2, December 2019, pp 96-106

p-ISSN: $1410-9840$ \& e-ISSN: 2580-8850

http://journals.usm.ac.id/index.php/jprt/index

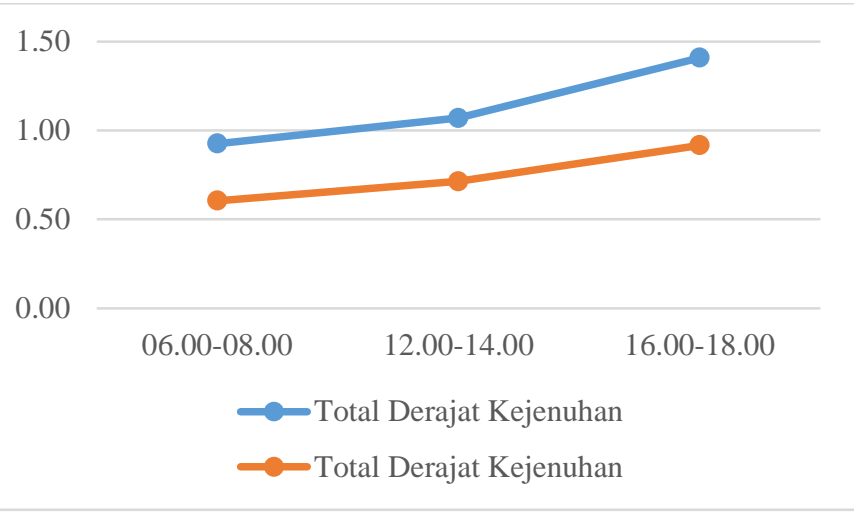

Gambar 2 Grafik perbandingan derajat kejenuhan

Dari grafik dan tabel 13 dapat di ketahui bahwa rata-rata derajat kejenuhan terbesar terjadi hari Senin 4 Maret 2019 pada pukul 16.00-18.00 yaitu sebesar 1,41. Hal ini menunjukan bahwa arus lalu lintas di jalan tersebut sangat padat dan sering terjadi kemacetan panjang.

Berikut akan ditampilkan rekapitulasi dari tingkat pelayanan arus jalan Meruya Selatan-Kembangan:

Tabel 14 Tingkat Pelayanan Ruas Jalan Rata-Rata Jalan Meruya Selatan

\begin{tabular}{|c|c|c|c|}
\hline No & Waktu & $\begin{array}{c}\text { Derajat } \\
\text { Kejenuhan }\end{array}$ & $\begin{array}{c}\text { Tingkat } \\
\text { Pelayanan }\end{array}$ \\
\hline 1 & \multicolumn{3}{|c|}{ Senin 4 Maret 2019} \\
\hline & $06.00-08.00$ & 0.93 & E \\
\hline & $12.00-14.00$ & 1.07 & $\mathrm{~F}$ \\
\hline & $16.00-18.00$ & 1.41 & $\mathrm{~F}$ \\
\hline \multirow[t]{4}{*}{2} & \multicolumn{3}{|c|}{ Sabtu 2 Maret 2019} \\
\hline & $06.00-08.00$ & 0.60 & $\mathrm{C}$ \\
\hline & $12.00-14.00$ & 0.71 & $\mathrm{C}$ \\
\hline & $16.00-18.00$ & 0.92 & E \\
\hline
\end{tabular}

Sumber : Hasil Perhitungan

Berdasarkan dari hasil tersebut didapat rata-rata derajat kejenuhannya adalah 0,94 . Maka menurut MKJI 1997 tingkat pelayanan ruas jalan Meruya Selatan,Kembangan, Jakart Barat di depan Universitas Mercu Buana adalah E.

\section{KESIMPULAN}

Berdasarkan dari hasil analisa dan pembahasan fasilitas pejalan kaki dan ruas jalan yang telah dilakukan di Jalan Meruya Selatan, Kembangan, Jakarta Barat didapat beberapa kesimpulan yaitu sebagai berikut : a. Volume pejalan kaki pada hari Senin 4 Maret 2019 adalah 4259 orang dan pada hari Sbatu 2 Maret 2019 sebanyak 5169 orang. Kecepatan rata-rata dalam pengamatan 2 hari adalah 368 $\mathrm{ft} /$ menit ke arah Joglo dan 401,15 ke arah Kembangan. Dengan rata-rata ruang bebas selama 2 hari pengamatan yaitu sebesar 82,70 $\mathrm{ft}^{2} /$ ped di depan UMB dan 94,26 $\mathrm{ft}^{2} /$ ped di seberang UMB. Dan fasilitas penyeberangan yang telah ada pada lokasi tersebut adalah zebra cross.

b. Tingkat pelayanan fasilitas trotoar di depan UMB menurut arus adalah $B$ dan tingkat peleyanan ruang pejalan kakinya adalah $\mathrm{B}$, sedangkan tingkat pelayanan menurut arus di seberang UMB adalah $\mathrm{B}$ dan tingkat pelayana ruang pejalan kakinya adalah $B$. Menurut analisa perhitungan $\mathrm{PV}^{2}$ fasilitas yang ada yaitu zebra cross tidak mencukupi kebutuhan penyebarangan bagi pejalan kaki. Hasil dari analisa pada lokasi tersebut nilai $\mathrm{PV}^{2}$ rata-rata pada lokasi tersebut adalah $2,05 \times 10^{9}$. Dimana menurut Tata Cara Perencanaan Fasilitas Pejalan Kaki di Kawasan Perkotaan ( Departemen Pekerjaan Umum Direktorat Jenderal Bina Marga Direktorat Bina Teknik / No : 011/T/Bt/1995 ) bahwa fasilitas penyeberangan yang sesuai pada lokasi tersebut adalah Pelican dengan lapak tunggu.

c. Menurut hasil analisa ruas jalan Meruya Selatan, Kembangan, Jakarta Selatan lebih tepatnya di depan Universitas Mercu Buana bahwa pelayanan ruas jalan tersebut didapat derajat kejenuhan rata-rata nya adalah 0,94 . Maka menurut MKJI 1997 tingkat pelayanan jalan ruas jalan tersebut adalah E. Dimana volume lalu lintas tersebut mendekati atau pada kapasitas arus yang tidak stabil yang dimana kecepatan kadang-kadang berhenti.

\section{SARAN}

a. Diaharapkan adanya studi selanjutnya dalam penentuan fasilitas penyeberangan pejalan kaki. Dengan mengamati perkembangan volume pejalan kaki dan lokasi penyeberangan selanjutnya, agar memberikan pelayanan dan keamanan bagi pejalan kaki menjadi lebih baik. 
Pengembangan Rekayasa dan Teknologi, Vol 15, No. 2, December 2019, pp 96-106

p-ISSN: $1410-9840$ \& e-ISSN: 2580-8850

http://journals.usm.ac.id/index.php/jprt/index

b. Pada fasilitas pejalan kaki yaitu trotoar terutama di seberang Universitas Mercu Buana sebaiknya diberi peringatan bagi yang suka memarkirkan kendaraan sepeda motornya di trotoar agar dialihkan ke tempat parkir Masjid Universitas Mercu Buana. Karena mengganggu pejalan kaki saat berjalan sehingga pejalan kaki terpaksa berjalan di jalan lalu lintas kendaraan bermotor, dan dapat meningkatkan kecelakaan bagi pejalan kaki dan kemacetan bagi arus lalu lintas di ruas jalan tersebut.

c. Pemerintah seharusnya lebih tanggap karena lingkungan pada ruas jalan tersebut semakin hari semakin berkembang dan membuat kebutuhan penyeberangan, trotoar dan ruas jalan tersebut harus segera dibenahi agar terhindar dari kemacetan dan kecelakaan yang tidak diinginkan.

d. Selanjutnya terkait hambatan samping pada ruas jalan tersebut. Lebih baik dibuatkan sarana transit atau shelter untuk menaikan dan menurunkan penumpang agar ojek online dan angkutan umum lainnya tidak asal menurunkan atau menaikan penumpang.

\section{DAFTAR PUSTAKA}

[1] Ardono, AT. 2009. STUDI KEBUTUHAN FASILITAS PENYEBERANGAN DI KOTA TANGGERANG (STUDI KASUS JL. JEND SUDRIMAN DAN JL. MH THAMRIN). S1 Thesis, Tanggerang: UNIVERSITAS MERCU BUANA.

[2] Budiawan, NF, dan Sukarno. 2015. Tingkat Pelayanan Fasilitas Pedestrian Di Simpang 